\title{
PENGETAHUAN SISWI KELAS XI TENTANG DAMPAK ANEMIA TERHADAP KESEHATAN REPRODUKSI
}

\author{
Clarita Angelina ${ }^{1}$, Debi Novita Siregar ${ }^{2}$, \\ Patimah Sari Siregar ${ }^{3}$, Elis Anggeria ${ }^{4}$ \\ ${ }^{1,2,3,4}$ Fakultas Keperawatan dan Kebidanan Universitas Prima Indonesia, Medan \\ Email: claritaangelina28@gmail.com; debinovitasiregar@yahoo.com; \\ patimahsari818@gmail.com; elisanggeria@unprimdn.ac.id
}

\begin{abstract}
Anemia is a clinical condition of reducing the quality of red blood cells. In circulation that is marked by low hemoglobin levels in the blood. The impact of anemia on iron nutrition results in a pale, weak, tired, dizzy, and decreased concentration of learning. Other causes: the level of knowledge of adolescent girls and the length of menstruation. The purpose of this study was to determine the description of class XI knowledge about the effects of anemia on reproductive health in SMA 6 Medan 2019. This research is descriptive using primary and secondary data. The populations in this study were 30 teenage girls in SMA 6 Medan as many as in-class XI IPA I. The sampling technique of this study was using purposive sampling technique. The sample of this study was 30 students. The results of this study indicate that the majority of people who lack knowledge are 16 people (54\%) and the minority of people who have good knowledge is 4 people $(13 \%)$. The study conclusion is that the majority of female student's knowledge about the effects of anemia on reproductive health is lacking. For the school and adolescents, it is hoped that they will increase their knowledge by came and working with health workers to promote health about the effect of anemia on reproductive health.
\end{abstract}

Keywords : knowledge, adolescents, anemia, health, reproductive

\section{PENDAHULUAN}

Masa remaja (Adolesscense) merupakan masa pertumbuhan dan berkembang yang di tandai dengan terjadinya perubahan sangat cepat baik secara fisik, psikis, dan kognitif (Fikawati, Syafiq, \& Veratamala, 2017). Menurut BKKBN tahun 2017, rentang usia remaja adalah 10 - 24 tahun dan belum menikah. Remaja putri merupakan salah satu kelompok yang rawan menderita anemia bersamaan dengan menstruasi yang akan mengeluarkan zat besi yang di perlukan untuk pembentukan hemoglobin.

(Handayani \& Hariwibowo, 2012).

World Health Organization (WHO) (2013), prevalensi anemia dunia berkisar 40-88\%. Jumlah penduduk usia remaja (10-19 tahun) di Indonesia sebesar $26,2 \%$ yang terdiri dari $50,9 \%$ laki-laki dan $49,1 \%$ perempuan (Kementrian Kesehatan, 2014).

Menurut Peraturan Menteri Kesehatan RI tahun 2014 remaja adalah penduduk dalam rentang usia 10-18 tahun (Kementerian Kesehatan RI, 2017). Pervalensi angka kejadian anemia di Indonesia sebanyak $21,7 \%$ 
berumur 5-14 tahun, remaja putri usia 10-18 tahun sebesar $57,1 \%$ dan usia 19 45 tahun sebesar $39,5 \%$ wanita mempunyai resiko anemia paling tinggi terutama pada remaja putri (Kemenkes RI, 2017). Remaja putri beresiko menderita anemia defisiensi besi dibandingkan dengan remaja putra. Anemia defisiensi besi merupakan penyebab anemia terbesar di Indonesia dan negara berkembang lainnya, lebih dari $50 \%$ anemia adalah anemia defisiensi besi (Briawan, 2014).

Hasil penelitian Sukartiningsih dan Amaliah (2018) didapatkan bahwa secara statistik bahwa faktor predisposisi dari kejadian anemia pada remaja putri berhubungan dengan variabel pengetahuan, sikap, diet, sedangkan faktor penguatnya adalah tenaga kesehatan. Anemia merupakan suatu kondisi klinis penurunan kuantitas selsel darah merah dalam sirkulasi yang ditandai dengan rendahnya kadar hemoglobin dalam (Bakta, 2014).

Penelitian Kaimudin, Lestari, \& Afa (2017) menyatakan asupan vitamin A berhubungan secara signifikan dengan kejadian anemia pada remaja putri SMA. Menurut Abdulsalam dan Daniel (2016) anemia defisiensi besi dapat menyebabkan terjadinya berbagai komplikasi antara lain berupa gangguan fungsi kognitif, penurunan daya tahantubuh, tumbuh kembang yang terlambat, penurunan aktivitas, dan perubahan tingkah laku.

Rata-rata remaja memiliki masalah mental emosiona lkategori borderline yang artinya remaja beresiko mengalami masalah psikososial yang akan berdampak kepada gangguan mental emosional dan mengganggu kesehatan jiwa remaja (Devita, 2019). Hal ini karena tingkat pendidikan orang tua, tingkat ekonomi, tingkat pengetahuan anemia dari remaja putri dan lamanya menstruasi. Jumlah penduduk usia remaja (10-19 tahun) sebesar 26,2\% yang terdiri dari 50,9\% laki-laki dan 49,1\% perempuan (Kemenkes RI, 2017).

Penelitian Prasetya dan Wihandani, (2019) menyatakan hubungan prestasi belajar yang sangat lemah antara siswi yang anemia dengan yang tidak anemia, tetapi secara statistik tidak bermakna. Penelitian Febrianti, Utomo, dan Adriana (2015) mendapatkan hubungan yang bermakna antara lama haid dengan kejadian anemia remaja putri. Variabel lain tidak memiliki hubungan yang bermakna dengan anemia.

Menstruasi adalah suatu keadaan fisiologis atau normal, merupakan peristiwa pengeluaran darah, lendir dan sisa-sisa sel secara berkala yang berasal dari mukosa uterus dan terjadi relatif teratur mulai dari menarche sampai 
menopause, kecuali pada masa hamil dan laktasi. Lama perdarahan pada menstruasi bervariasi, pada umumnya 46 hari, tapi 2-9 hari masih dianggap fisiologis (Kurniawan, 2016).

Prevalensi anemia pada perempuan dewasa mencapai $25 \%$, laki-laki dewasa $26,8 \%$, dan anak-anak $14,5 \%$ di Sumatera Utara dan menurut survei anemia dilaksanakan pada tahun 2016 di empat kabupaten/kota di Sumatera utara yaitu Kota Medan, Kota Binjai, Kabupaten Deli serdang dan Langkat diketahui bahwa $40,5 \%$ remaja putri menderita anemia terutama anemia zat besi (Dinas Kesehatan Provinsi Sumatera utara, 2016).

Berdasarkan hasil survei awal di SMA Negeri 6 Medan yang dilakukan pada tanggal 06 April 2019. Pada saat melakukan survei pada siswi kelas XI di SMA Negeri 6 Medan terdapat 10 orang dilakukan wawancara dan hanya 2 orang yang mengerti dan memahami tentang dampak anemia terhadap kesehatan reproduksi, dan 8 orang tidak mengetahui anemia dapat terjadi dan dampak pada kesehatan reproduksi.

\section{METODE}

Jenis penelitian ini bersifat deskritif. Penelitian deskriptif yaitu penelitian yang menggambarkan pengetahuan siswi kelas XI tentang dampak anemia terhadap kesehatan reproduksi di SMA
Negeri 6 Medan tahun 2019. Penelitian ini dilakukan pada bulan Juli 2019.

Populasi dalam penelitian ini siswi remaja putri di SMA Negeri 6 Medan sebanyak 30 orang siswi putri pada kelas XI IPA I. Teknik pengambilan sampel dalam penelitian ini menggunakan Purposive Sampling, menentukan pengambilan sampel dengan cara menetapkan populasi digunakan sebagai sampel (Notoatmodjo, 2012a). Pengambilan sampel dilakukan sebanyak 30 orang. Kriteria Inklusi antara lain: digunakan sebagai pendekatan untuk membangun pengetahuan baik dari responden mengikutsertakan umur dan pendidikan. Metode pengumpulan data menggunakan data primer dan sekunder

Analisa data dilakukan secara deskriptif dengan melihat presentase terkumpul dan disajikan dalam tabel distribusi frekuensi kemudian dilanjutkan dengan membahas hasil penelitian berdasarkan teori dan keperpustakaan yang ada.

\section{HASIL DAN PEMBAHASAN}

Berdasarkan hasil penelitian yang dilakukan mengenai gambaran pengetahuan siswi kelas XI tentang dampak anemia terhadap kesehatan reproduksi, maka didapat hasil sebagai berikut: 
Tabel 1. Distribusi Frekuensi Pengetahuan Siswi Kelas XI Tentang Dampak Anemia Terhadap Kesehatan Reproduksi

\begin{tabular}{ll}
\hline No. & Pengetahuan \\
\hline 1. & Baik \\
2. & Cukup \\
3. & Kurang \\
\hline \multicolumn{3}{c}{ Jumlah } \\
\hline \multicolumn{3}{c}{ Berdasarkan tabel 1 menunjukan } \\
bahwa mayoritas responden memiliki \\
pengetahuan kurang sebanyak 16 orang \\
(16\%) dan minoritas berpengetahuan \\
baik sebanyak 4 orang (13\%).
\end{tabular}

\section{Pembahasan}

Berdasarkan hasil penelitian yang dilakukan oleh peneliti mengenai gambaran pengetahuan siswi kelas XI tentang dampak anemia terhadap kesehatan reproduksi di SMA Negeri 6 Medan tahun 2019 didapatkan mayoritas responden yang memiliki pengetahuan yang kurang sebanyak 16 orang (54\%) dan minoritas yang berpengetahuan baik sebanyak 4 orang (13\%).

Pengetahuan meliputi penalaran, penjelasan dan pemahaman manusia tentang segala sesuatu juga mencakup praktek atau kemampuan teknis dalam memecahkan berbagai persoalan hidup (Notoatmodjo, 2012b). Pengetahuan Anemia pada siswi remaja sangat kurang dari segi pemahaman sehingga kemampuan dalam menangani masalah dampak anemia masih rentan untuk dilaksanakan.
Persentase

(\%)

(n)

13

33

$\begin{array}{lr}10 & 33 \\ 16 & 54\end{array}$

$30 \quad 100$

Menurut Mularsih

(2017) menunjukkan adanya hubungan signifikan antara pengetahuan remaja putri tentang anemia dengan perilaku pencegahan anemia pada saat menstruasi. Penelitian Martini (2015) mendapatkan faktor-faktor yang berhubungan dengan anemia adalah status gizi, pengetahuan, dan pendidikan ibu. Penelitian Harahap menunjukkan bahwa terdapat hubungan yang signifikan dengan kejadian anemia pada remaja putri adalah pengetahuan, pendapatan orangtua, status gizi dan menstruasi. Sedangkan variabel yang tidak berhubungan secara signifikan adalah tingkat pendidikan orangtua.

Berdasaran hasil penelitian ini mayoritas responden yang memiliki pengetahuan kurang sebanyak $16 \%$. Hal ini karena pengetahuan dapat dipengaruhi oleh faktor internal, melaui pendidikan yaitu arahan yang diberian kepada orang lain agar dapat memahami suatu hal. Semakin tinggi pendidikan seseorang akan semakin mudah menerima informasi (Wawan \& Dewi, 2012). 
Menurut asumsi peneliti pengetahuan kurang dapat dipengaruhi oleh tingkat pengetahuan, pemahaman, dan penerapan mengenali dampak anemia Hal ini dapat dilihat adanya responden kurang memahami anemia merupakan suatu kondisi meningkatnya sel darah merah dalam peredaran darah. Sebanyak $40 \%$ kurang memahami bahwa kekurangan zat besi pada remaja dapat menyebabkan anemia. Sebanyak 20\% kurang memahami banyaknya darah yang keluar pada saat menstruasi $2 \mathrm{x}$ lebih dari biasanya hingga mengganti pembalut lebih dari 4 kali sehari bisa akan menyebakan anemia.

Sebanyak $43 \%$ kurang memahami kemampuan berfikir secara rasional akan mencapai prestasi di sekolah ini termasuk kemampuan dalam pemahaman. Sebanyak $46 \%$ kurang memahami bahwa vitamin B12 salah satu penghambat pembentukan dari sel darah merah. Sebanyak 23\% kurang memahami klasifikasi anemia hemolitik merupakan penghancuran / pemecahan sel darah merah yang lebih cepat pembuatannya. Sebanyak 30\% kurang mengerti bahwasanya teh dan kopi adalah salah satu penghambat dari zat besi. Sebanyak $46 \%$ kurang memahami bahwa makan- makanan gizi seimbang serta asupan zat besi yang cukup salah satu pencegahan anemia. Sebanyak 30\% kurang memahami konsentrasi perilaku menurun pada remaja di karenakan dampak dari anemia.

Sebanyak 30\% kurang memahami bahwa anemia tidak berpengaruh pada pertumbuhan fisik pada remaja. Sebanyak 23\% kurang memahami kesehatan reproduksi merupakan suatu keaadaaan sejahtera fisik, mental, dan sosial secara utuh semata-mata bebas dari penyakit maupun kecacatan. Sebanyak 23\% kurang memahami tentang faktor kesehatan reproduksi bukan merupakan dari pengetahuan, sikap serta lingkungan dan sumber informasi. Sebanyak 20\% kurang memahami lamanya perputaran jarak/ waktu menstruasi pada wanita berkisar 28-35 hari. Sebanyak 23\% kurang memahami bahwa anita biasanya mengeluarkan darah saat menstruasi mengganti pembalut \pm 6 kali dalam 1 hari.

Penelitian Solehati, Trisyani, dan Kosasih (2018) pada variabel pengetahuan dan sikap tentang perawatan saat menstruasi ditemukan bahwa semua responden berpengetahuan buruk dan sebagian besar responden sebanyak $78 \%$ memiliki sikap tidak mendukung terhadap perawatan saat menstruasi. Penelitian Rapa (2019) mendapatkan masih terdapat siswi yang berpengetahuan kurang dan bersikap negatif tentang menstruasi. 
Berdasarkan hasil penelitian ini juga mendapatkan responden yang memiliki pengetahuan yang cukup sebanyak 33\% pengetahuan ini dikarenakan responden siswi telah menerapkan dalam kehidupan sehari-harinya dan dan mengenali bahwa menstruasi pada remaja putri dapat menyebabkan anemia yang akan berdampak terhadap kesehatan reproduksinya.

Menurut asumsi penelitian pengetahuan cukup sebanyak 63\%, dikarenakan responden cukup memahami kadar hemoglobin wanita usia 15-49 tahun normalnya 12,0 g/dl. Sebanyak $63 \%$ dapat memahami perubahan pada wajahnya yang pucat, kepala terasa pusing ketika lama berdiri, lemas, lesu, sering cepat lelah merupakan tanda-tanda gejala anemia.

Hasil penelitian Nurhafni (2017) menjelaskan tentang tingkat pengetahuan remaja tentang anemia di SMA PABA Binjai menunjukan bahwa pengetahuan remaja anemia preventif yang cukup memerlukan $53 \%$ dan mendukung tentang tanda-tanda dan gejala anemia $58,7 \%$ dan memerlukan pengetahuan cukup $65,94 \%$.

Berdasarkan hasil penelitian ini responden dengan pengetahuan baik sebanyak $10 \%$. Pengetahuan baik dapat dipengaruhi oleh faktor pendidikan. Usia juga mempengaruhi pola pikir seseorang, dan dengan bertambahnya usia semakin berkembang kognitif seseorang.

Menurut asumsi peneliti, pengetahuan siswi dipengaruhi oleh pengalaman responden dalam menstruasi. Mereka memahami tanda dan gejala dari anemia, sehingga remaja putri dapat mengantisipasi kejadian anemia. Hasil penelitian Fajriyah (2016) mendapatkan bahwa sebagian besar yaitu remaja putri tidak mengetahui tentang anemia. Perlu adanya upaya untuk melakukan kegiatan yang berkaitan dengan pendidikan kesehatan tentang bahaya anemia dan cara pencegahannya agar kejadian anemia pada remaja putri dapat ditanggulangi.

Sedangkan hasil penelitian Suryani, Hafiani, dan Junita (2017) menunjukkan prevalensi anemia pada remaja sebesar 43\% dan pola makan remaja tidak baik $79,2 \%$, tidak terdapat hubungan antara pengetahuan tentang anemia dengan kejadian anemia dan tidak terdapat hubungan antara pola makan dengan kejadian anemia.

Hasil observasi ditemuan sebanyak 73\% responden memahami anemia merupakan suatu keadaan dimana kadar hemoglobin $(\mathrm{Hb})$ dalam darah lebih rendah dari pada nilai normal. Sebanyak $70 \%$ remaja mengetahui melalui sumber informasi apabila kadar anemia hemoglobinya $9 \mathrm{~g} / \mathrm{dl}$. Sebanyak $77 \%$, oksigen yang kurang dalam otak 
akan mengurangi pengambilan sel darah merah. Sebanyak $77 \%$ mengetahui bahwa kekurangan oksigen dalam otak dapat menurunkan kemampuan kosentrasi belajar pada remaja.

\section{KESIMPULAN DAN SARAN}

\section{Kesimpulan}

Gambaran pengetahuan siswi kelas XI tentang dampak anemia terhadap kesehatan reproduksi di SMA negeri 6 medan tahun 2019 Mayoritas responden berpengetahuan kurang sebanyak 16 orang (54\%).

\section{Saran}

\section{Bagi Responden}

Diharapkan kepada semua siswi agar tetap menambah pengetahuannya tentang dampak anemia yang bisa mereka dapatkan melalui sumber informasi baik tenaga kesehatan, dari pendidikan agar pengetahuan siswi bertambah serta dapat memahami bahkan tau cara mencegah tanda gejala dari anemia yang berdampak pada kesehatan reproduksi.

\section{Bagi Peneliti Selanjutnya}

Diharapkan peneliti selanjutnya untuk melanjutkan penelitian dengan menghubungkan masalah gizi anemia pada siswi dari berbagai aspek untuk memperoleh hasil yang lebih baik lagi dan meningkatkan hasil penelitian untuk kedepannya.

3. Bagi Tempat Peneliti
Peneliti diharapkan pada pihak sekolah SMA Negeri 6 Medan bagi guru berkerjasama dengan tenaga kesehatan agar dapat memberikan bimbingan dan pengarahan kepada remaja putri tentang Dampak Anemia Terhadap Kesehatan Reproduksi.

4. Bagi Institusi Pendidikan

Diharapkan hasil penelitian ini dapat di jadikan sebagai salah satu sumber informasi mengenai dampak terjadinya anemia terhadap kesehatan reproduksi, dan bagi mahasiswa Universitas Prima Indonesia khususnya Kebidanan.

\section{DAFTAR PUSTAKA}

Abdulsalam, M., \& Daniel, A. (2016). Diagnosis, pengobatan dan pencegahan anemia defisiensi besi. Sari Pediatri. https://doi.org/10. 14238/sp4.2.2002.74-7

Bakta, I. M. (2014). Pendekatan terhadap pasien anemia. In Imu Penyakit Dalam.

Briawan, D. (2014). Anemia masalah gizi pada remaja wanita. Jakarta: EGC.

Devita, Y. (2019). Prevalensi masalah mental emosional remaja di Kota Pekanbaru. Jurnal Keperawatan Priority.

Dinas Kesehatan Provinsi Sumatera utara. (2016). Profil kesehatan provinsi sumatera utara tahun 2016. In http://www.depkes.go.id/resources /download/profil/PROFIL_KAB_KO TA_2016/1275_Sumut_Kota_Medan _2016.pdf.

Fajriyah, N. N. (2016). Gambaran tingkat pengetahuan tentang anemia pada remaja putri. Jurnal Ilmiah Kesehatan.

Febrianti, F., Utomo, W., \& Adriana, A. (2015). Lama haid dan kejadian anemia pada remaja putri. Jurnal 
Kesehatan

Reproduksi.

https://doi.org/10.22435/kespro.v4i1

Apr.3897.11-15

Fikawati, S., Syafiq, A., \& Veratamala,

A. (2017). Buku gizi anak dan remaja.

Handayani, W., \& Hariwibowo, A. S. (2012). Buku ajar asuhan keperawatan pada klien dengan gangguan sistem hematologi.

Harahap, N. R. (2018). Faktor- faktor yang berhubungan dengan kejadian anemia pada remaja putri. Nursing Arts. https://doi.org/10.36741/jna.v12i2.78

Kaimudin, N. La, Lestari, H., \& Dkk. (2017). Skrining dan determinan kejadian anemia pada remaja putri SMA Negeri 3 Kendari tahun 2017. Jurnal Ilmiah Mahasiswa Kesehatan Masyarakat.

Kemenkes RI. (2017). Pedoman pelaksanaan pemantauan status gizi (PSG) tahun 2017. Direktorat Gizi Masyarakat.

https://doi.org/10.1017/CBO9781107 415324.004

Kementerian Kesehatan RI. (2017). Infodatin reproduksi remaja-Ed.Pdf. Situasi Kesehatan Reproduksi Remaja.

Kementrian Kesehatan. (2014). Profil Kesehatan Indonesia Tahun 2013. In Jakarta: Kementerian Kesehatan RI. https://doi.org/351.770.212 Ind P

Kurniawan. (2016). Fisologi siklus menstruasi. Kesehatan.

Martini. (2015). Faktor - faktor yang berhubungan dengan kejadian anemia pada remaja putri di Man 1 Metro. Jurnal Kesehatan Metro Sai Wawai.

Mularsih, S. (2017). Hubungan pengetahuan remaja putri tentang anemia dengan perilaku pencegahan anemia pada saat menstruasi di SMK Nusa Bhakti Kota Semarang. Jurnal Kebidanan.

https://doi.org/10.26714/jk.6.2.2017. 80-85

Notoatmodjo, S. (2012a). Metodologi penelitian kesehatan (Cetakan VI)
[JOUR]. Jakarta: Penerbit PT. Rineka Cipta.

Notoatmodjo, S. (2012b). Promosi Kesehatan \& Ilmu Perilaku. In Jakarta: Rineka Cipta.

Nurhafni. (2017). Tingkat pengetahuan remaja tentang anemia pada remaja di SMA Paba Binjai tahun 2015. Jurnal Ilmiah Kohesi, 1(1).

Prasetya, K. A. H., \& Wihandani, D. M. (2019). Hubungan antara anemia dengan prestasi belajar pada siswi kelas XI di SMAN I ABIANSEMAL BADUNG. E-Jurnal Medika Udayana. https://doi.org/10.24922/eum.v8i1.45 757

Rapa, A. (2019). Gambaran pengetahuan dan sikap remaja putri Kelas VII tentang menstruasi di SMPN 2 Kapala Pitu tahun 2018. MPPKI (Media Publikasi Promosi Kesehatan Indonesia): The Indonesian Journal of Health Promotion. https://doi.org/10.31934/mppki.v2i2. 564

Solehati, T., Trisyani, M., \& Kosasih, C. E. (2018). Gambaran pengetahuan, sikap, dan keluhan tentang menstruasi diantara remaja puteri. Jurnal Keperawatan Komprehensif. https://doi.org/10.33755/jkk.v4i2.110

Sukartiningsih, M. C. E., \& Amaliah, M. (2018). Faktor yang berhubungan dengan kejadian anemia pada remaja putri di Wilayah Kerja Puskesmas Kambaniru Kabupaten Sumba Timur. 3(1), 16-29.

Suryani, D., Hafiani, R., \& Junita, R. (2017). Analisis pola makan dan anemia gizi besi pada remaja putri Kota Bengkulu. Jurnal Kesehatan Masyarakat Andalas. https://doi.org/10.24893/jkma.v10i1. 157

Wawan, A., \& Dewi, M. (2012). Teori dan pengukuran pengetahuan, sikap dan perilaku manusia. In Nuha Medika. https://doi.org/10.1017/CB O9781107415324.004 